\title{
Flegmasía cerúlea dolens bilateral de origen desconocido
}

\author{
Bilateral phlegmasia cerulea dolens of unknown origin \\ Mauricio Gonzalez-Urquijo, Gabriela Cassagne y Mario A. Fabiani" \\ Tecnológico de Monterrey, Escuela de Medicina y Ciencias de la Salud, Monterrey, N.L., México
}

Paciente masculino de 56 años, sin antecedentes médicos de importancia, acude al departamento de urgencias refiriendo inflamación en ambas piernas desde hace siete días, con cambio en la coloración de la piel. A la exploración física el paciente presentaba frecuencia cardiaca $110 \mathrm{lpm}$, tensión arterial 90/60 $\mathrm{mmHg}$, frecuencia respiratoria de 18 y $36.6 \stackrel{\circ}{\circ}$ de temperatura. El único hallazgo patológico lo constituían ambos miembros pélvicos cianóticos y con bulas, hipotermia en ambas piernas y sin pulsos palpables. Asimismo, presentaba hipoestesia táctil y térmica debajo de las rodillas. Se realizó ultrasonido Doppler, encontrando trombosis venosa profunda desde tibiales hasta femorales, permeabilidad de venas iliacas, sin oscilación con movimientos respiratorios. El sistema arterial era permeable, pero con espectro bifásico debajo de las rodillas y reducción en los picos de velocidades sistólicas. La radiografía de tórax y el electrocardiograma eran normales. Se inicio anticoagulación endovenosa y no fue posible realizar estudio tomográfico por la inestabilidad hemodinámica. El paciente falleció cinco horas posteriores a su ingreso. La flegmasía cerúlea dolens es una rara complicación de la trombosis venosa profunda, causada por una oclusión venosa ocasionando isquemia y necrosis. Esta condición es mayormente vista en pacientes con cáncer (hasta en un $40 \%$ de los casos) o en estados hipercoagulables ${ }^{1,2}$. Otras causas incluyen trauma, filtros de vena cava y síndrome de May-Thurner. Un 10\% de los casos se presentan de forma idiopática. Esta

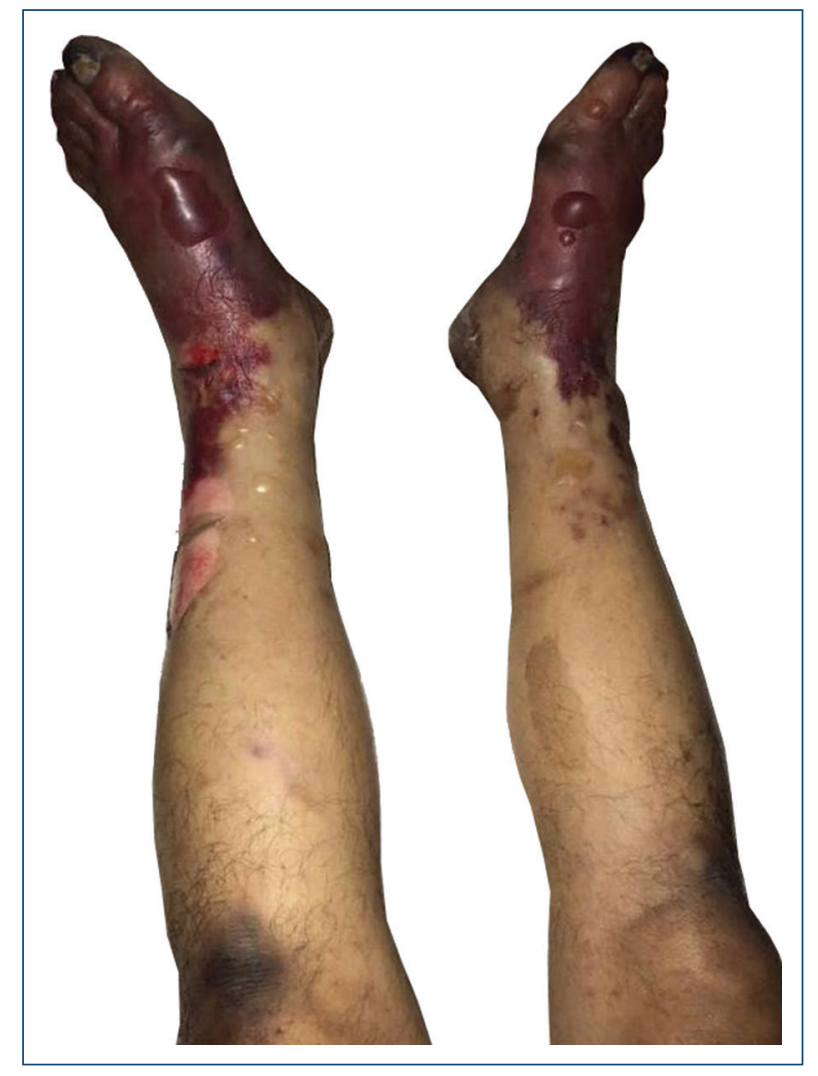

Figura 1. Paciente con coloración marmórea y bulas en ambos pies secundario a trombosis venosa profunda.

condición tiene una mortalidad del 25 al 40\%, siendo la gangrena venosa y el choque las causas más frecuentes de muerte ${ }^{3}$.

\section{Correspondencia:}

*Mario A. Fabiani

E-mail: alefabiani@gmail.com
Fecha de recepción: 13-05-2020

Fecha de aceptación: 07-12-2020 DOI: 10.24875/ACM.20000217
Disponible en internet: 19-05-2021 Arch Cardiol Mex. 2021;91(4):510-511 www.archivoscardiologia.com 1405-9940 / (C) 2020 Instituto Nacional de Cardiología Ignacio Chávez. Publicado por Permanyer. Este es un artículo open access bajo la licencia CC BY-NC-ND (http://creativecommons.org/licenses/by-nc-nd/4.0/). 


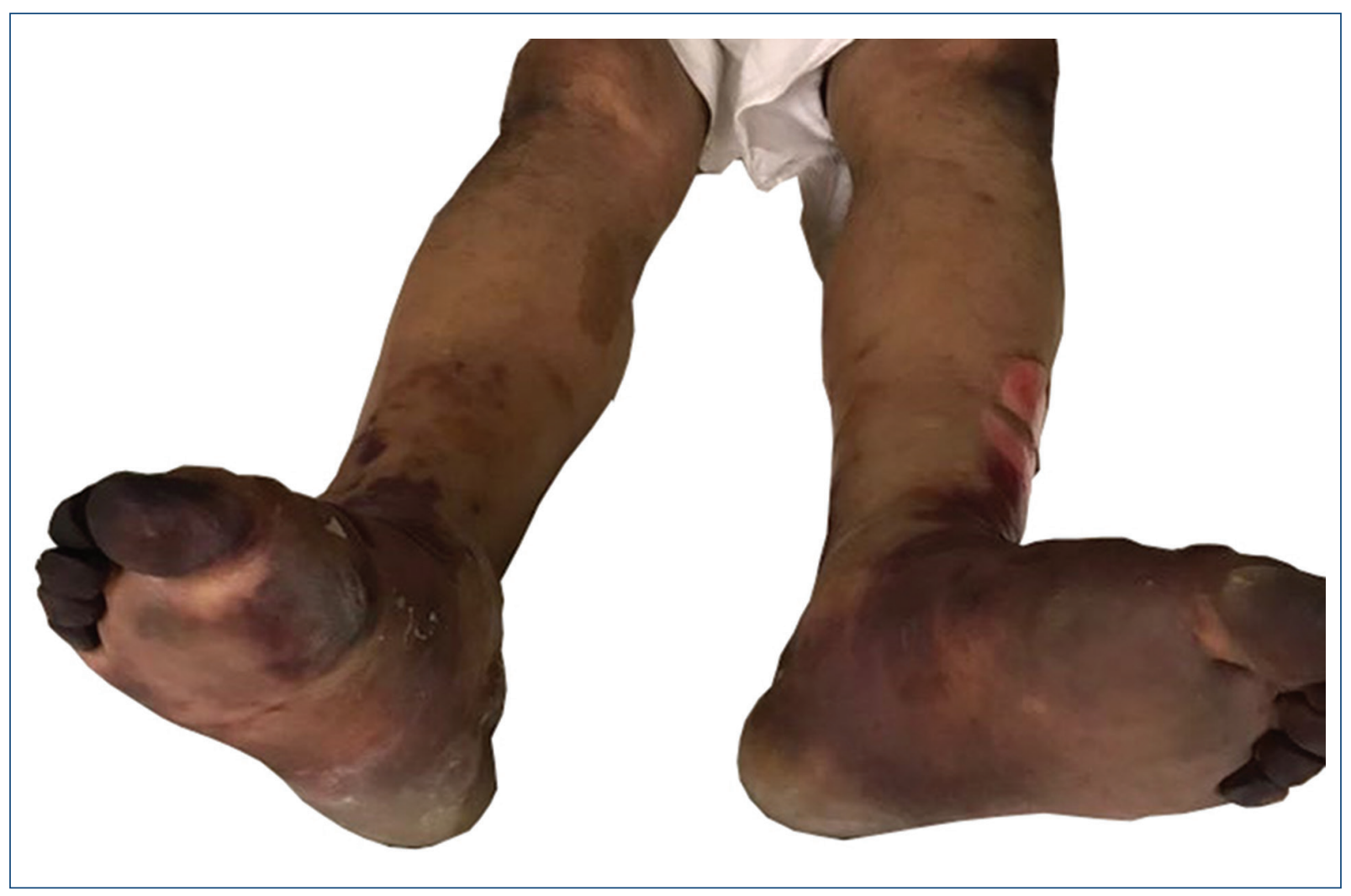

Figura 2. Necrosis de ambos pies secundaria a flegmasia cerúlea dolens bilateral.

\section{Financiamiento}

La presente investigación no ha recibido ayudas específicas provenientes de agencias del sector público, sector comercial o entidades sin ánimo de lucro.

\section{Conflicto de intereses}

Los autores declaran no tener conflicto de intereses.

\section{Responsabilidades éticas}

Protección de personas y animales. Los autores declaran que los procedimientos seguidos se conformaron a las normas éticas del comité de experimentación humana responsable y de acuerdo con la Asociación Médica Mundial y la Declaración de Helsinki.
Confidencialidad de los datos. Los autores declaran que han seguido los protocolos de su centro de trabajo sobre la publicación de datos de pacientes.

Derecho a la privacidad y consentimiento informado. Los autores han obtenido el consentimiento informado de los pacientes $y / 0$ sujetos referidos en el artículo. Este documento obra en poder del autor de correspondencia.

\section{Bibliografía}

1. Kaplan J, Nesheiwat Z, Kanwal A, Bahoora J. Unprovoked bilateral phlegmasia cerulea dolens: A case report. Arterioscler Thromb Vasc Biol. 2019;39:A474.

2. Lipe DN, Cuthbert D. Rare case of unilateral phlegmasia cerulea dolens with bilateral deep vein thrombosis at a community military hospital emergency department. Mil Med. 2017;182(5):e1823-e1825.

3. Joya M, Khatib P, Simon EL. Rapid deterioration and death caused by bilateral phlegmasia cerulea dolens. Emerg Med. 2018;50(5):107-9. 